Proceedings of SALT 22: 441-460, 2012

\title{
It-clefts are IT (inquiry terminating) constructions *
}

\author{
Dan Bridges Velleman \\ University of Texas \\ Emilie Destruel \\ University of Texas \\ Edgar Onea \\ University of Göttingen
}

\author{
David Beaver \\ University of Texas \\ Dylan Bumford \\ New York University \\ Liz Coppock \\ Heinrich Heine University
}

\begin{abstract}
We analyze the semantics of a range of constructions which we refer to as Inquiry Terminating (IT) constructions. In English, these include it-clefts and exclusives such as only, just and mere(ly). Despite their differences, IT constructions have much in common. We claim they are always focus- sensitive, have closely related semantics, and have a uniform discourse function: they always mark utterances that give a complete answer to what the speaker takes to be the Current Question (CQ). We give a new account of the meaning of clefts that captures both their similarities and their differences to other IT constructions.
\end{abstract}

Keywords: it-clefts, exhaustivity, focus sensitivity, discourse, question under discussion

\section{Introduction}

We present a semantic analysis of the English it-cleft, concentrating on the exhaustive meaning which the cleft introduces. Our analysis has two novel aspects. The first novel aspect concerns the relationship of the it-cleft with focus. Clefts are generally regarded as focus-marking constructions. On the simplest account, the entire pivot of a cleft is taken to be focused. But in fact this is not necessarily the case. We discuss examples in which only a portion of the pivot is focused-and show that in these examples, the location of focus within the pivot is crucial in determining the exhaustive meaning which arises.

* Research at the University of Texas was supported by NSF grant BCS-0952862 Semantics and Pragmatics of Projective Meaning across Languages, as well as by NSF BCS-0904913, and DoD HHM402-10-C-0100. 
(1) a. It was [John's eldest daughter $]_{F}$ who liked the movie.

$\rightarrow$ No other people liked the move.

b. It was John's [eldest $]_{F}$ daughter who liked the movie.

$\rightarrow$ None of John's other daughters liked the movie.

c. It was [John's $]_{F}$ eldest daughter who liked the movie.

$\rightarrow$ Nobody else's eldest daughter liked the movie.

Let's assume that the cleft construction introduces a semantic operator-call it CLEFT $_{S}$ - into the logical form of a sentence, and that this operator is responsible for the exhaustive component of its meaning. We argue based on examples like (1) that $\mathrm{CLEFT}_{S}$ must be a focus sensitive operator; based on further evidence we show that it must be a conventionally focus-sensitive operator in the sense of Beaver \& Clark $(2003,2008){ }^{1}$

The second novel aspect of our analysis concerns the relationship between itclefts and exclusive particles such as only. It has often been noted that it-clefts and only-sentences are semantically similar. This has motivated a number of what we will call symmetrical analyses. On these analyses, clefting and only introduce exactly the same exhaustive meaning component, and differ only in the at-issueness of that component-with utterances of only-sentences asserting exhaustivity and utterances of $i t$-clefts presupposing or conventionally implicating it.

Now, the symmetry between it-clefts and only-sentences does not fully determine how clefts should be analyzed - for there are also a number of different accounts that can be given of only. The novel move we make here is to adopt a particular recent account, by Coppock \& Beaver (2011), of only and other exclusive particles. We show that an account of $i t$-clefts which is symmetrical with this Coppock and Beaver account of exclusives has certain advantages. In particular, it solves a problem concerning the projection of exhaustivity from under negation and other scopetaking operators. We outline the problem in $\$ 2.3$ of the current paper, and our solution in $\$ 4.2 .^{2}$

The Coppock and Beaver account highlights the discourse function of exclusive particles: commenting on the relative strength of different answers to the Current Question under discussion (hereafter CQ), and their quantifier-like effects are shown to be consequences of this discourse function. This account is based on two operators,

1 We are tipping our hand here by calling the operator CLEFT $S$ rather than just CLEFT. The subscript $S$ indexes the current context; we use this index in order to retrieve $C Q_{S}$, the Current Question under discussion in that context, which is necessary in order to implement Beaver-and-Clark-style focus sensitivity.

2 The problem in question was most recently discussed by Büring (2011), and our solution has some interesting parallels with Büring's proposed solution. In particular, in cases where focus-sensitivity does not need to be considered, we generate the same predictions as Büring does. But in cases such as (1) where focus-sensitivity does need to be considered, the two accounts diverge in their predictions. 
It-clefts are IT constructions

$\operatorname{MIN}_{S}$ and MAX . The $\operatorname{MIN}_{S}$ term, which is presupposed, requires that there be a true answer to the CQ above a certain lower bound. The $\mathrm{MAX}_{S}$ term, which is at-issue, requires that there be no true answer to the CQ above a certain upper bound. (We will offer formal denotations for $\operatorname{MIN}_{S}$ and $\mathrm{MAX}_{S}$ in Section 4.2 after introducing some relevant background. For now, we give paraphrases only.)

(2) Only $[\text { Mary }]_{F}$ laughed.

$\lambda w: \operatorname{MIN}_{S}($ laughed $(m))(w) \cdot \operatorname{MAX}_{S}($ laughed $(m))(w)$

a. Requires a question of the form "Who laughed?"

b. Presupposes that at least Mary laughed.

c. Asserts that there is no true answer strictly stronger than "Mary laughed."

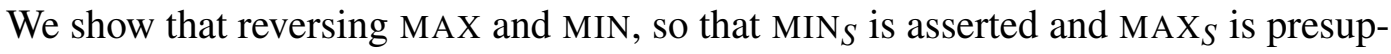
posed, gives a suitable denotation for the CLEFT $_{S}$ operator, exemplified in (3).

(3) It was $[\text { Mary }]_{F}$ who laughed.

$\lambda w: \operatorname{MAX}_{S}($ laughed $(m))(w) \cdot \operatorname{MIN}_{S}($ laughed $(m))(w)$

a. Requires a question of the form "Who laughed?"

b. Presupposes that there is no true answer strictly stronger than "Mary laughed."

c. Asserts that at least Mary laughed.

Based on these arguments, we suggest that it-clefts and exclusive particles such as only belong to a single broader family of "inquiry terminating constructions" or "IT-constructions." These constructions have a common pragmatic function: they mark an answer to the current question under discussion as a maximal answer, thereby resolving the question and terminating it as an active line of inquiry. ITconstructions vary along several axes, most of which are already present in the Coppock and Beaver taxonomy of exclusive particles: different IT-constructions may have different semantic types, and may point to different sorts of scale along which an answer may count as maximal. To these, we add a third axis of variation: different IT-constructions may differ as to whether the truth of the answer itself or the maximality of the answer is at-issue.

\section{Past approaches}

Clefts give rise to exhaustivity inferences, as shown by the contrast between (4a) and (4b). While a plain sentence predicating laughing of an individual can be followed by another one predicating laughing of another individual as in (4a), its cleft counterpart 
(4b) is infelicitous, because the cleft conveys that the pivot (John) exhausts the list of laughers.

(4) a. JOHN laughed, and so did MARY.

b. \#It was JOHN who laughed, and so did MARY.

In this section we discuss several analyses of the exhaustive meaning component that have been offered over the years, and introduce the classic data which these analyses attempt to account for.

\subsection{Exhaustivity as an entailment}

Since Horn (1981) it has largely been assumed that exhaustivity cannot be treated as an entailment. But prior to Horn's work several authors took this approach. Bolinger (1972) takes clefts to be true copular clauses, entailing equality between a pair of NPs, so that from the sentence in (5) we derive the meaning in (5a). Atlas \& Levinson (1981) take a similar approach, using an early version of Structured Meanings to separate out what they take to be the at-issue and not-at-issue parts of the meaning; their proposed meaning is shown in (5b). Another possible approach, reminiscent of Russell's analysis of definite noun phrases and shown in (5c), is the one Szabolcsi (1981) uses for the exhaustive meaning of preverbal foci in Hungarian. In all three cases, the English sentence in $(5 \mathrm{~d})$ can be taken as a rough gloss.

(5) It was Mary that laughed.

a. $\{m\}=\{x \mid$ laughed $(x)\}$

(Bolinger 1972)

b. $[\lambda x \cdot x=m](\gamma x[$ laughed $(x)])$

(Atlas \& Levinson 1981)

c. laughed $(m) \wedge \forall x[$ laughed $(x) \rightarrow x=m]$

(Szabolcsi 1981)

d. "The group of people who laughed is the group that contains Mary and nobody else"

Horn (1981) argued that approaches along these lines are inadequate, based on the data in $(6 a-c)$. In more modern terminology than Horn used, we would say that the problem in each case is the not-at-issueness of the exhaustive component of the cleft's meaning. In (6a), the result is pragmatic oddity due to uninformativeness-the at-issue part of the cleft's meaning does not actually tell us anything new. In (6b), the result is outright contradiction, because negation targets the at-issue part of the cleft's meaning. In both cases, an expression which clearly makes exhaustivity at-issue will be felicitous, as in ( $7 a$ and $b)$. 
It-clefts are IT constructions

(6) I know Mary ate a pizza...

a. \#but I've just heard it was a pizza she ate.

b. \#but it wasn't a pizza she ate.
(7) I know Mary ate a pizza...

a. but I've just heard she only ate a
pizza.

b. but she didn't only eat a pizza.

\subsection{Exhaustivity as a pragmatic implicature}

Horn's proposal, following the argument described above, was to treat exhaustivity as a quantity implicature. He claims that any expression which presupposes $\exists x[P(x)]$ and goes on to assert $P(a)$ gives rise to the inference that $a$ is the only relevant individual satisfying $P$; the reasoning is that if there were other relevant individuals satisfying $P$, the speaker would have mentioned them as well.

But this approach runs into trouble quickly. Conversational implicatures are generally taken to be cancellable, but the exhaustivity of a cleft is not easily cancelled.

(8) \#It was pizza Mary ate; indeed, it was pizza and a calzone.

Horn's own response to this difficulty was to question whether all conversational implicatures must be cancellable. But most subsequent authors took a different route: taking both the entailment account and the pragmatic implicature account to be discredited, they have argued that exhaustivity arises out of a presupposition of some sort.

\subsection{Exhaustivity as a presupposition}

Another possibility is to treat the exhaustivity of a cleft as a presupposition. The question here is what form the presupposition should take; various proposals have been made, but either they run into empirical problems or they ignore the symmetry between it-clefts and only-sentences.

On this approach, the basic challenge is to characterize the presupposition in such a way that it does not make the entailed content of a cleft trivial. In particular, it is generally accepted that clefts have an existential presupposition, of the form (9a). ${ }^{3}$ Observe, then, what happens if we posit the naïve exhaustive presupposition in (9b). Taken together, $(9 a-b)$ entail the truth of the prejacent in $(9 c)$. This means that in any situation in which the presuppositions in $(9 a-b)$ were met, there would be no need to utter the cleft at all. Even if we assume that the presuppositions in

3 Though Büring (2011) has argued against the existential presupposition; see further discussion in $\S 4.3$ of the current paper. 
(9a-b) can be accommodated, so that the cleft can be uttered in contexts where they are not already part of the common ground, it will still be the case that there is no informative content left in the cleft once the hearers have accommodated its presuppositions. And this seems like a problem; we would expect a sentence with no informative entailments to sound odd or redundant, and the fact that clefts often don't sound redundant suggests that this is not the right approach. ${ }^{4}$

\section{(9) An unworkable presuppositional account}

It was Mary who laughed.
a. $\exists x[$ laughed $(x)]$
Existential presupposition
b. $\forall x[\operatorname{laughed}(x) \rightarrow(x=m)]$
Exhaustive presupposition
c. laughed $(m)$
Entailed prejacent

A further difficulty with (9) involves the fact that presuppositions project. The naïve version of the exhaustive presupposition sketched there should not be allowed to project, or we will predict infelicity for perfectly good sentences such as (10).

(10) It wasn't Mary who laughed; it was Bill.

A similar problem with projection affects other presupposition based accounts. For instance, Halvorsen (1978) suggested that clefts presuppose uniqueness, using the formula in (11); but Atlas \& Levinson (1981) point out that this falsely predicts infelicity for the felicitous sentence in (12). ${ }^{5}$

$$
\exists x[\forall y[\operatorname{laughed}(y) \rightarrow y=x]]
$$

Uniqueness presupposition

(12) It wasn't Mary who laughed; it was Bill and Sue.

Büring (2011) suggests another way to solve these problems. He makes his exhaustive presupposition conditional, as in (13). This approach does not suffer the problems of a naïve exhaustive presupposition: (13a) and (13b) do not entail the truth of (13c), and so the entailment of the cleft remains non-trivial.

4 Sometimes a sentence with no informative at-issue content will be used in discourse, generally as a reminder or an acknowledgement. And clefts can be used as reminders or acknowledgements. But if they were consistently uninformative, and only usable in the same contexts in which other uninformative sentences could be used, then we'd expect that clefts would always serve as reminders or acknowledgements. And this is not the case.

5 Atlas and Levinson's counterexample is only effective if our model does not include group entities. On the other hand, if our model does contain group entities, presupposing uniqueness will have other unpleasant effects. 
It-clefts are IT constructions

(13) It was Mary who laughed.

a. Existential implicature: Someone laughed.

b. Conditional exhaustive presupposition: If Mary laughed, then nobody else did.

c. Entailed prejacent: Mary laughed

What's more, it makes significantly better predictions for negated clefts. However, it still runs into empirical difficulties, as we discuss in $\S 3$.

\section{Very dull parties and other risks of syntactic exhaustification: Why clefts must be focus-sensitive}

Of the approaches we have discussed so far, the conditional presupposition approach comes closest to empirical adequacy. But there is a further empirical problem that all of the approaches so far mentioned are subject to. These approaches posit too strong a connection between syntax and semantics: the entire cleft pivot, and only the pivot, is exhaustified. And this is not always correct. Consider the sentence in (14a): here, all of the accounts which we have considered give incorrect predictions.

(14) a. It was John's ELDEST daughter who attended the party.

b. ...His OTHER daughters DIDN' T go.

In each case, the problem is the same: the pivot John's eldest daughter is predicted to exhaustify the open proposition " $x$ attended the party," which would lead to the inference that there was only one person at the party: John's eldest daughter. Contrary to their predictions, this inference does not arise: note the felicity of (15a). What actually happens is that the focused portion of the pivot, eldest, is taken to exhaustify the open proposition "John's $p$ daughter attended the party." We can see this exhaustivity effect from the infelicity of (15b).

(15) It was John's ELDEST daughter who attended the party...

a. $\ldots$ and 200 of her closest friends were there.

b. \#... and John's YOUNGEST daughter was ALSO there.

c. .... and MARY'S eldest daughter was ALSO there.

This suggests that the exhaustive component of a cleft's meaning is focussensitive. Further evidence comes from shifting the location of focus within a pivot. For instance, the focus structure in (16) is also possible, 
(16) a. It was JOHN's eldest daughter who attended the party.

b. ... Everyone ELSE just sent their YOUNGER children.

and this leads to a different exhaustive inference, as shown by the judgements in (17).

(17) It was JOHN's eldest daughter who attended the party...

a. $\quad \ldots$ and 200 of her closest friends were there.

b. .... and John's YOUNGEST daughter was ALSO there.

c. \#... and MARY's eldest daughter was ALSO there.

Beaver \& Clark (2003) point out that not all focus-sensitive expressions are the same. On the one hand, they show, a small number of operators are conventionally focus sensitive: their lexical entries make explicit reference to the current question under discussion. This category includes the exclusives only, mere(ly), sole(ly) and so on, the additives also and too, and the scalar additive even. On the other hand, there are operators whose meaning interacts with focus in non-conventionalized, pragmatically mediated ways. This latter category of operators is much larger. It includes all non-veridical propositional operators, and all quantificational expressions with implicit domain restriction; classic examples include not (Jackendoff 1972) and adverbs of quantification such as always (Lewis 1975). ${ }^{6}$

So the question now arises, which sort of focus-sensitivity is the it-cleft exhibiting? The evidence suggests it belongs to the smaller former category: it is conventionally focus-sensitive. We base this conclusion on a diagnostic described by Beaver and Clark. They show that conventionally focus-sensitive operators must have a focus within their scope with which they can associate. They cannot associate with prosodically reduced words such as clitic pronouns (18a-b). Whereas non-conventionally focus-sensitive operators, such as not and always, are free from this restriction and can associate with reduced words $(18 \mathrm{c}-\mathrm{d})$.

(18) You can see John, but can you see Mary?

a. Actually, I can ONLY see MARY / see HER / \# see 'er. (Conventional)

b. Yes-I can ALSO see MARY / see HER / \# see 'er. (Conventional)

c. No-I CAN'T see MARY / see HER / see 'er. (Non-conventional)

d. Yes-I can ALWAYS see MARY / see HER / see 'er. (Non-conventional)

6 Beaver and Clark propose different mechanisms of pragmatic focus sensitivity for the nonveridical operators on the one hand and the quantificational expressions on the other; but this distinction need not concern us here, since $\mathrm{CLEFT}_{S}$ turns out to be conventionally rather than pragmatically focus-sensitive. 
It-clefts are IT constructions

It-clefts pattern like conventionally focus-sensitive items with respect to this diagnostic.

(19) Actually, it's MARY / it's HER / \# it's 'er who I CAN see.

This suggests that the logical form of an it-cleft contains a conventionally focussensitive operator. Let us assume that the logical form of an English it-cleft contains some operator $\mathrm{CLEFT}_{S}$ which is responsible for the exhaustive meaning of the cleft. What we have shown in this section is that the semantic representation for CLEFT $_{S}$ must make reference to the CQ, just as the semantic representations for even, also, only and so on do.

We adopt the Beaver and Clark account of conventional focus-sensitivity. On this account:

- Conventionally focus-sensitive operators have a denotation which refers to the current question under discussion $\left(C Q_{S}\right)$.

- Focus-marking (realized prosodically in English) constrains the current question using a mechanism similar to the one proposed by Rooth (1992).

We do not provide a full account of question-answer congruence here. But we do note that in general, an it-cleft is a felicitous answer to the same questions as its non-cleft "counterpart." There is a slight complication here: in some contexts, a cleft will sound odd as an immediate, direct answer to an overt question. On our hypothesis that clefts are IT-constructions, marking the end of a line of inquiry, the reason for this is clear: an explicit IT-construction is unnecessary in contexts where there is no extended inquiry which needs to be terminated. (Note that adding a more extended inquiry, as in (21), significantly improves the example.)

(20) A: What did Mary eat?

? B: It was a PIZZA that Mary ate.

(21) A: What did Mary eat?

C: I thought she said she was gonna get a pizza, but I might be wrong.

D: And did she also order a salad?

B: Guys, I was there. And C's right-it was a PIZZA that Mary ate.

Still, this is not a constraint on the CQs that a cleft can answer. The requirement is simply that the CQ have been raised or discussed in such a way that a marked inquiry-terminating move is appropriate. With this caveat, any CQ congruent with the non-cleft sentence Mary ate $a$ PIZZA is also congruent with the cleft sentence $I t$ was a PIZZA that Mary ate. We assume that this particular parallel between cleft and non-cleft sentences holds more generally. 
We can now sketch an account of the focus-sensitivity of the cleft sentence It was John's ELDEST daughter who attended the party. We assume that it has the same CQ-congruence possibilities as its non-cleft counterpart John's ELDEST daughter attended the party. This means the CQ must include alternatives of the form "John's $x$ daughter attended the party." One salient question of this form is "Which of John's daughters attended the party?" Assuming that interlocutors have accepted this as the CQ, or can accommodate it as the CQ, the result will be an exhaustive inference relative to that question, indicating that "It was John's ELDEST daughter who attended" is the strongest or most complete true answer.

In the next section, we outline a formal account of how this exhaustivity inference arises.

\section{Towards a formal account}

We propose an account quite similar to Coppock \& Beaver's (2011) account of exclusive particles such as only. On their account, an exclusive particle has two meaning components: $\operatorname{MIN}_{S}(p)$, which ensures that there is a true answer to the CQ which is at least as strong as the prejacent $p$, and $\operatorname{MAX}_{S}(p)$, which ensures that no true answer is strictly stronger than $p$. We will present formal definitions for both operators in $\S 4.2$, after giving a bit more background information.

We show in this section that $\operatorname{CLEFT}_{S}(p)$ should be analyzed as having the same two meaning components. The only difference is what's at-issue: clefts make the MIN component at issue, while only makes the MAX component at-issue. We show that all differences in behavior between clefts and only sentences can be derived from this difference in at-issueness.

Interestingly, in those cases where the focus-sensitivity of CLEFT $S$ can be ignored, our account makes the same predictions as the conditional presupposition proposed by Büring (2011). In particular: when the entire pivot, and only the pivot, is focused, then $\operatorname{MAX}_{s}(p)$ and Büring's conditional presupposition have exactly the same effects. On the other hand, in those cases discussed in the previous section, in which the pivot and the focused part of the cleft are not coextensive, the two accounts diverge. In those cases, it is our account which makes the correct predictions.

\subsection{MIN and MAX}

On the Coppock and Beaver theory of exclusives, the meanings of all exclusive particles are defined in terms of two focus-sensitive operators, MIN ${ }_{S}$ and $\operatorname{MAX}_{S}$. (The subscript $S$ here indexes the current context.) We will argue for a parallel definition of the semantic contribution of English it-clefts, using these same two operators.

Let the context $S$ include a Current Question $C Q_{S}$; let it also include a salient 
It-clefts are IT constructions

partial ordering over the alternatives in $C Q_{S}$, indicated by the relations $\left(\geq_{S}\right)$ and $\left(>_{S}\right)$. We now define $\operatorname{MIN}_{S}$ and $\mathrm{MAX}_{S}$ as follows: ${ }^{7}$
a. $\operatorname{MIN}_{S}(p)=\lambda w . \exists q \in C Q_{S}\left[q(w) \wedge\left(q \geq_{S} p\right)\right]$
"There's a true answer at least as strong as $p . "$

b. $\operatorname{MAX}_{S}(p)=\lambda w . \forall q \in C Q_{S}\left[\left(q>_{S} p\right) \rightarrow \neg q(w)\right]$

"No true answer is strictly stronger than $p . "$

According to Coppock and Beaver, a declarative utterance of only $p$ presupposes $\operatorname{MIN}_{S}(p)$ and asserts $\operatorname{MAX}_{S}(p)$.

$$
\llbracket \text { only } \rrbracket=\lambda w \cdot \lambda p: \operatorname{MIN}_{S}(p)(w) \cdot \operatorname{MAX}_{S}(p)(w)
$$

Note that we have not specified how alternatives in $C Q_{S}$ should be ordered. Indeed, various orderings are possible. One important feature of the Coppock and Beaver account is that it allows different particles to specify requirements regarding the nature of the ordering. For instance, mere and merely require the alternatives to be ordered with respect to rank or importance; only is more flexible and is compatible with different scale types.

Especially important for our purposes is the entailment scale, on which $p \geq_{S} q$ iff $p$ entails $q$, and $p>_{S} q$ iff $p$ both entails and is distinct from $q$. An entailment scale over Hamblin answers gives rise to a boolean lattice, like the one shown in Figure 1. Here the current question is something like "Who laughed?" and the domain of possible laughers is restricted to three individuals: Alice, Bob and Carol. (We assume that $D_{e}$ includes groups such as $a \oplus b$ - the group consisting of Alice and Bob-as well as individuals such as $a$, and that laughed is a distributive predicate, such that a group laughed iff every member of the group did so.)

Consider the effect of an utterance of "Only Alice laughed" in the context whose CQ - with alternatives ranked on an entailment scale-is represented by Figure 1. Given the proposal for $\mathrm{ONLY}_{S}$ given above, this utterance presupposes $\operatorname{MIN}_{S}($ laughed $(a))$ and asserts $\operatorname{MAX}_{S}($ laughed $(a))$. The presupposition imposes the requirement that there be a true answer in the following set:

$$
\{\text { laughed }(a), \text { laughed }(a \oplus b), \text { laughed }(a \oplus c), \text { laughed }(a \oplus b \oplus c)\}
$$

which consists of laughed $(a)$ and those answers strictly stronger than it. On the other hand, the assertion tells us that no answer strictly stronger than laughed $(a)$ is

7 Note that our definition of $\mathrm{MAX}_{S}$ differs slightly from the one used in Coppock and Beaver. The change does not lead to different predictions for the meaning of exclusive particles; but it does make a difference when it comes to the meaning of clefts. 


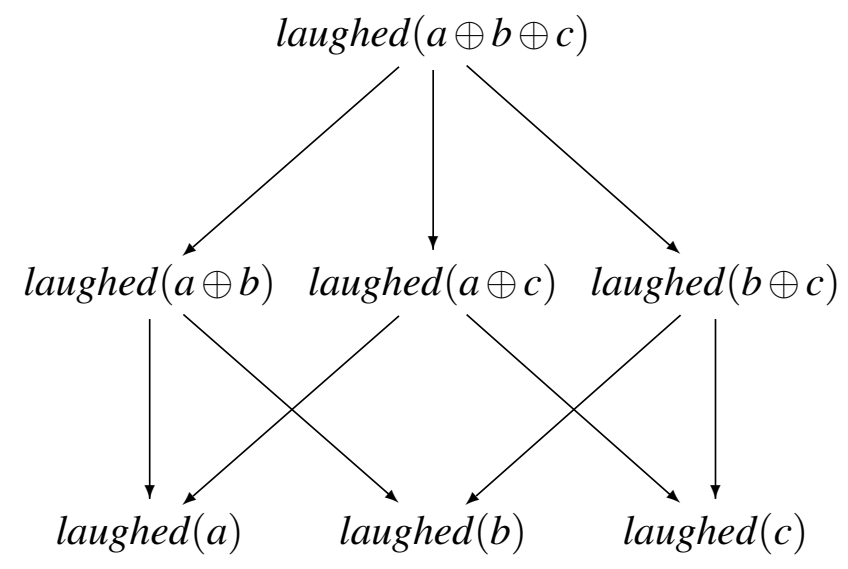

Figure 1 The structure of an entailment scale, corresponding to the question "Who laughed?" with a three-person domain.

true. So by process of elimination, $\operatorname{laughed}(a)$ is true and the stronger answers in the set are not:

$$
\text { laughed }(a) \quad \neg \text { laughed }(a \oplus b) \quad \neg \text { laughed }(a \oplus c) \quad \neg \text { laughed }(a \oplus b \oplus c)
$$

Finally, from the above premises we can infer that $\neg$ laughed $(b)$ and $\neg$ laughed $(c)$. Thus we get the exhaustive inference that nobody other than Alice laughed.

Note that a different $C Q$ would have led to a different exhaustive meaning in this example. Coppock and Beaver (following Beaver \& Clark (2008) and building on work by Rooth (1992)) use this to capture the focus-sensitivity of only. Since the focal alternatives of an utterance must be congruent to the CQ-call this the Focus Principle-utterances with different focus structures will make different CQs possible.

\subsection{The proposal}

Our definition of $\mathrm{CLEFT}_{S}$ is symmetrical with the account sketched above of the meaning of only. What only marks as presupposed, CLEFT $S$ makes at-issue, and vice versa:
a. $\llbracket$ only $\rrbracket=\lambda w \cdot \lambda p: \operatorname{MiN}_{S}(p)(w) \cdot \operatorname{MAX}_{S}(p)(w)$
b. $\operatorname{CLEFT}_{S}=\lambda w \cdot \lambda p: \operatorname{MAX}_{S}(p)(w) \cdot \operatorname{MIN}_{S}(p)(w)$ 
It-clefts are IT constructions

This means, for instance, that in unembedded contexts, "It was Alice who laughed" triggers the same inferences as "Only Alice laughed." The MIN component requires that some answer at least as strong as laughed $(a)$ be true; the MAX component requires that no answer stronger than laughed $(a)$ be true; and we infer as a result that Alice laughed and that nobody other than Alice laughed.

In a moment, we will turn to examine this account's predictions in embedded contexts, where we will see that it makes more accurate projection predictions than other symmetrical accounts. But before doing that, let us spend a bit more time on other aspects of its predictions in unembedded contexts.

First, we note that like previous symmetrical ccounts, ours describes a difference

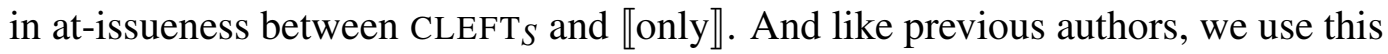
to explain the asymmetry in informativeness betwee it-clefts and only-sentences. We repeat the relevant data in (25-26).

I know Mary ate a pizza. . .

a. \#but I've just heard it was a pizza she ate.

b. \#but it wasn't a pizza she ate.
(26) I know Mary ate a pizza...

a. but I've just heard she only ate a pizza.

b. but she didn't only eat a pizza.

Note that $\operatorname{MIN}_{S}(p)$ is not informative in a context that already entails $p .{ }^{8}$ On the other hand, $\operatorname{MAX}_{S}(p)$ is informative in such a context. We assume a constraint like the following (cf. Stalnaker 1979):

Informativeness: The at-issue content of an utterance must be informative relative to the common ground.

This immediately predicts that " $p$ and $\operatorname{ONLY}_{S}(p)$ " will be good (since the at-issue content of $\operatorname{ONLY}_{S}(p)$ is informative in this context), but that " $p$ and $\operatorname{CLEFT}_{S}(p)$ " will be bad (since its at-issue content is uninformative).

Second, let us note that this proposal also lets us capture the behavior discussed in Section 3, in which narrow focus within the pivot can shift the meaning of a cleft. For instance, for the sentence in (28), we generate the focal alternatives in (28a), suggesting that the CQ should be along the lines of (28b). ${ }^{9}$

8 The crucial fact here is that, on an entailment scale, if $p \in C Q_{S}$, then $p \models \operatorname{MIN}_{S}(p)$. In other words, any time $p$ has been asserted, $\operatorname{MIN}_{S}(p)$ will be part of the common ground. So for instance, in (25), after the first clause, it is common ground that $\operatorname{MIN}_{S}(\llbracket$ Mary ate a pizza $\rrbracket)$. And now recall that the sole at-issue component of $\operatorname{CLEFT}_{S}(p)$ is $\operatorname{MIN}_{S}(p)$. This explains the sense that an utterance of the cleft sentence in (25a) would be redundant in the context given: everything which the sentence makes at-issue is already in the common ground. On the other hand, an only-sentence such as (26a) does not suffer this problem, for only-sentences make $\operatorname{MAX}_{S}(p)$ at-issue and $\operatorname{MAX}_{S}(p)$ is not entailed by $p$.

9 Note that this is not necessarily the only possible CQ here. For instance, on certain assumptions, a 
(28) It was John's ELDEST daughter who attended.

a. $\quad\left\{\llbracket\right.$ John's $\alpha$ daugher attended $\left.\rrbracket \mid \llbracket \alpha \rrbracket \in D_{\text {et }}\right\}$

b. Which of John's daughters attended?

The MIN and MAX operators now operate over the answers to this CQ. The resulting inference is now that of the sentences in (29), only "John's eldest daughter attended" is true. Note that this is completely consistent with the possibility that more than one person attended the party—so long as the remaining attendees are not among John's daughters. And this is just what we need.

John's eldest daughter attended,

John's second daughter attended,

John's youngest daughter attended

\subsection{Clefts under embedding}

The difference in at-issueness between it-clefts and only sentences, discussed above, can explain why the two constructions behave so differently in embedded contexts. In each case, it is the at-issue component of the meaning that is targeted by negation and other scope-taking operators; the presupposed component projects. This leads us to predict, for instance, the following denotations:

$\llbracket$ Not only Alice laughed $\rrbracket=\lambda w: \operatorname{MIN}_{S}($ laughed $(a))(w) \cdot \neg \operatorname{MAX}_{S}($ laughed $(a))(w)$

$\llbracket$ It wasn't Alice who laughed $=\lambda w: \operatorname{MAX}_{S}(\operatorname{laughed}(a))(w) \cdot \neg \operatorname{MIN}_{S}(\operatorname{laughed}(a))(w)$

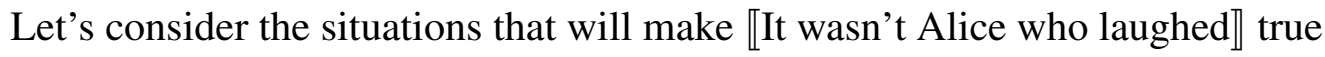
on this account. Its at-issue component, $\neg \operatorname{MIN}_{S}($ laughed $(a))$, is true iff there are no true answers stronger than or equal to laughed $(a)$. This amounts to the claim that Alice didn't laugh, and neither did any group containing her:

$$
\begin{aligned}
\neg \operatorname{MIN}_{S}(\text { laughed }(a)) \models \neg \text { laughed }(a) & \wedge \neg \text { laughed }(a \oplus b) \\
& \wedge \neg \text { laughed }(a \oplus c) \wedge \neg \text { laughed }(a \oplus b \oplus c)
\end{aligned}
$$

question would be possible that we might paraphrase thus: "The daughter of John's who attendedwhat properties does she have?" If a hearer were to generate this as the CQ, though, they would immediately run into pragmatic oddity-for (28) would then suggest that John has a daughter who has the property of being the eldest and no other properties whatsoever: no name, no physical features, no personality, and so on. This is quite unlikely to be true, and so the CQ that leds to this reading would be rejected. 
It-clefts are IT constructions

But since laughed is a distributive predicate, this is just the same as saying Alice didn't laugh.

$$
\neg \operatorname{MIN}_{S}(\text { laughed }(a))=\neg \text { laughed }(a)
$$

The presupposed component, $\operatorname{MAX}_{S}($ laughed $(a))$, makes a strictly weaker claim, that no answer strictly stronger than laughed $(a)$ is true-or in other words, no larger group including Alice laughed, though Alice alone might have.

$$
\operatorname{MAX}_{S}(\text { laughed }(a)) \models \neg \text { laughed }(a \oplus b) \wedge \neg \text { laughed }(a \oplus c) \wedge \neg \text { laughed }(a \oplus b \oplus c)
$$

In other words, the effect of It wasn't Alice who laughed is to presuppose that no larger group including Alice laughed, and to assert in addition that Alice herself didn't laugh.

This explains the felicity of the sentences in (30). After all, we are not presupposing anything about the cardinality, specificity or uniqueness of the set of laughers.

(30) a. It wasn't Alice who laughed, it was Bob and Carol.

b. It wasn't Alice who laughed, it was everyone else in the room.

We do, on the other hand, predict that (31) should be infelicitous.

(31)??It wasn't Alice who laughed, it was Alice and Bob.

Note, though, that this prediction depends crucially on the fact that laughed is a distributive predicate. If we replace it with a non-distributive predicate, as in (32), we predict felicity. Let $m$ stand for "moved the sofa," and $o$ refer to (the group consisting of) the other movers besides Alice. It can be true that $m(a \oplus o)$ and still false that $m(a)$. This means that there is no entailment relationship between the two propositions, which in turn means that they are unordered with respect to one another, and so applying $\operatorname{MAX}_{S}$ to either one will not rule out the other, suggesting that (32) will be consistent. This matches our intuitions - though we must admit that these are subtle intuitions, and further empirical evidence here would be helpful.

(32) It wasn't ALICE who moved the sofa, it was Alice AND the OTHER movers.

Finally, with a little extra work, we can account for the oddity of (33).

(33) \#It wasn't Alice who laughed; nobody laughed.

We will need two assumptions here. First: given the question "who laughed?" we treat "nobody laughed" as a rejection of the question rather than an answer to it. (Thus, if it is indeed true that nobody laughed, the question "who laughed?" is 
unanswerable, and can only be dealt with by rejecting it.) Second: we assume a principle to the effect that unanswerable questions should be rejected as soon as possible - that it is misleading or uncooperative, if you know a question to be unanswerable, to go on discussing it as if nothing were wrong. On those assumptions, (33) involves just such a misleading or uncooperative move; for the first sentence indicates that we have a CQ along the lines of "who laughed?" while the second sentence indicates that such a CQ should have been rejected all along. ${ }^{10}$

In this way, we account for the data which has previously been called an existential presupposition for cleft sentences. On our account, it is not strictly speaking the cleft itself which triggers an existential inference; it is the CQ which the cleft indicates. And the existential inference is to some extent defeasible-we can block it by rejecting the question which was responsible for it.

Büring gives a different argument against the existential presupposition, based on examples such as (35) — in which, he points out, B's reply does not presuppose "someone called Mary."

\section{A: I know John and Mary spoke. But who called who? \\ B: It was JOHN who called MARY.}

But there is indeed an existential inference that arises from (35), namely "someone called someone." This is another case where it is crucial to recognize the focus sensitivity of the cleft operator. The most likely CQ in (35) contains two alternatives: $\{$ called $(j, m)$, called $(m, j)\}$. If we do not reject the question (thus implying we think it is answerable), this will indeed imply a belief that someone called someone. And so we get an existential inference after all, though it is not the one which a non-focus-sensitive account would predict.

10 On the other hand, there is a variant of (33) which—as Keenan (1971) pointed out—is felicitous:

((i)) You claim that someone laughed. But it wasn't Alice who laughed; it wasn't Bob; it wasn't Carol; it wasn't Dave... I think you're wrong. I think nobody laughed.

This variant can be understood as involving a sort of reductio ad absurdum strategy. Rather than rejecting the question "who laughed?" straight away, the speaker accepts it for the sake of argument, in order to demonstrate in detail why it cannot be answered.

Note too that the badness of (32) is reduced if we add some indication that the speaker has done a bit of extra thinking in between sentences. (34) is okay, because we are free to assume that the speaker hadn't yet realized the need to reject the question when he addressed it in his first sentence.

(34) It wasn't Alice who laughed. You know, actually, come to think of it, nobody laughed.

A fuller account is needed of the circumstances under which questions can be accepted or must be rejected. We do not attempt to provide such an account; what we have shown here is that, were such an account to be provided, our analysis of the it-cleft would be able to dovetail with it in an explanatorily useful way. 
It-clefts are IT constructions

\section{Discussion and conclusions}

We have argued that the meanings of only-sentences and it-clefts in English are quite closely related. Both are introduced by a focus-sensitive operator, both are comprised of the same two meaning components, and the primary difference between the two appears to be a difference in at-issueness between those two components.

In the past, words such as only, mere(ly), sole(ly), just and so on have been taken to form a class of exclusive particles. Since the focus-sensitive CLEFT $S$ operator is introduced by a syntactic construction, perhaps it is better now to speak of a class of constructions rather than a class of particles. What's more, if the account we offer is correct, the function of these constructions is not primarily exclusive, or indeed quantificational at all. On our account, they serve a discourse function: they mark an answer to the CQ as a maximal answer, indicating that the line of inquiry represented by that question has been fully explored and can now be closed. In other words, what we have here is a class of inquiry terminating constructions, or IT-constructions for short.

Of course, there are ways to close a line of inquiry that don't require the use of an IT-construction. For instance, we can give a complete answer in canonical word order, using firm, confident declarative prosody. If B's contribution in (36) is uttered

with a low boundary tone indicating finality, rather than with the high boundary tone that marks partial answers and tentative statements, it too will be taken to have an exhaustive meaning - quite similar in fact to the meaning of "it was Mary who laughed."

$$
\begin{aligned}
& \text { A: Who laughed? } \\
& \text { B: MARY laughed. }
\end{aligned}
$$

We can think of this as pragmatic termination of a line of inquiry. Note that, like many other pragmatic inferences, it appears to be cancellable. No matter how firm and conclusive B's prosody is, he is free to continue as in (37).

$$
\text { B: MARY laughed. So did JOHN. }
$$

And this is precisely what we cannot do after an it-cleft.

(38) \# B: It was MARY who laughed. And so did JOHN.

To make a long story short, there are several ways to terminate a line of inquiry. We can use a canonical-order sentence with no exclusive particle - in which case the inquiry terminating effect has the status of a cancellable pragmatic inference, with prosody and context as contributing factors. Or we can use an ITconstruction, in which case the inquiry terminating effect is conventionally marked 
and uncancellable. Furthermore, if we choose an IT-construction, we can make the inquiry-terminating effect - the maximality of the stated answer-either at-issue or not-at-issue. In any of these cases, the precise semantics of the inquiry terminating move will depend in part on what line of inquiry we are currently engaged in-or, in more formal terms, on the Current Question, which is in turn reflected by the placement of focus within the sentence.

There is no reason to assume that other languages provide fewer options. Indeed, it appears that a full complement of IT-constructions can be found in other languages. It is well known that exclusive particles, which make the inquiry terminating effect at-issue, exist throughout the languages of the world. (König 1991 claims that every language has at least one.) And we have identified several constructions in other languages that have an effect much like English it-clefts: a not-at-issue inquiry terminating effect (Velleman, Beaver, Bumford, Destruel \& Onea 2011). These include the c'est-cleft in French (Destruel 2012) and the preverbal focus construction in Hungarian (Wedgwood 2005; Onea \& Beaver 2011).

\section{References}

Atlas, J.D. \& Stephen C. Levinson. 1981. It-clefts, informativeness and logical form: radical pragmatics (revised standard version). In P. Cole (ed.), Radical pragmatics, New York: Academic Press.

Beaver, David I. \& Brady Z. Clark. 2003. Always and only: why not all focussensitive operators are alike. Natural Language Semantics 11(4). 323-362.

Beaver, David I. \& Brady Z. Clark. 2008. Sense and Sensitivity: How Focus Determines Meaning. Wiley-Blackwell.

Bolinger, Dwight. 1972. A look at equations and cleft sentences. In E. Firchow (ed.), Studies for Einar Haugen, 96-114. The Hague: Mouton de Gruyter.

Büring, Daniel. 2011. Conditional exhaustivity presuppositions in clefts (and definites). Ms. under submission.

Coppock, Elizabeth \& David Beaver. 2011. Sole sisters. In Semantics and Linguistic Theory (SALT) 21, 197-217.

Destruel, Emilie. 2012. The French c'est-cleft: an empirical study on its meaning and use. Manuscript to appear in Empirical Issues in Syntax and Semantics 9, collected papers from CSSP 2011.

Halvorsen, Per-Kristian. 1978. The syntax and semantics of cleft constructions. In Texas Linguistic Forum 11, Austin: University of Texas.

Horn, Laurence R. 1981. Exhaustiveness and the semantics of clefts. In New England Linguistic Society (NELS) 11, 125-142.

Jackendoff, Ray. 1972. Semantic Interpretation in Generative Grammar. Cambridge, MA: MIT Press. 
It-clefts are IT constructions

Keenan, Edward. 1971. Two kinds of presupposition in natural language. In Charles Fillmore \& D. Terence Langendoen (eds.), Studies in Linguistic Semantics, 45-54. New York: Holt, Reinhart and Winston.

König, E. 1991. The Meaning of Focus Particles: A Comparative Perspective. New York: Routledge.

Lewis, David. 1975. Adverbs of quantification. In E.L. Keenan (ed.), Formal Semantics of Natural Language, Cambridge.

Onea, Edgar \& David I. Beaver. 2011. Hungarian focus is not exhausted. In Ed Cormany, Satoshi Ito \& David Lutz (eds.), Semantics and Linguistic Theory (SALT) 19, 342-359.

Rooth, Mats. 1992. A theory of focus interpretation. Natural Language Semantics 1(1). 75-116.

Stalnaker, Robert. 1979. Assertion. In Syntax and Semantics, vol. 9, Academic Press.

Szabolcsi, Anna. 1981. The semantics of topic-focus articulation. In Jan Groenindijk et al. (ed.), Formal Methods in the Study of Language, Amsterdam: Matematisch Centrum.

Velleman, Daniel B., David I. Beaver, Dylan Bumford, Emilie Destruel \& Edgar Onea. 2011. 'Yes, but...': exhaustivity and at-issueness across languages. Presentation at PEPA 3 poster session.

Wedgwood, Daniel. 2005. Shifting the Focus: From Static Structures to the Dynamics of Interpretation. Amsterdam: Elsevier.

Dan Bridges Velleman

University of Texas

CLA 4.304, Mailcode B5100

Austin, TX 78712

dvelleman@gmail.com

Emilie Destruel

University of Texas

CLA 4.304, Mailcode B5100

Austin, TX 78712

emiliedestrueljohnson@gmail.com
David Beaver University of Texas

CLA 4.304, Mailcode B5100

Austin, TX 78712

dib@mail.utexas.edu

Dylan Bumford

NYU Department of Linguistics

10 Washington Place,

New York, NY 10003

dbumford@gmail.com 
Velleman, Beaver, Destruel, Bumford, Onea and Coppock

Edgar Onea

Georg-August-Universität Göttingen

Nikolausberger Weg 23

D-37073 Göttingen

Germany

edgar.onea@zentr.uni-goettingen.de
Liz Coppock

University of Gothenburg

Box 200

40530 Gothenburg

Sweden

eecoppock@gmail.com 